\title{
Hot Air Assisted Infrared Drying of Vegetables and Its Quality
}

\author{
Kalathur Harishchandra Vishwanathan, Hungalore Umesh HebBaR*, \\ Kurumanchi Shreesaila Mallikarjuna Srinivasa RaghaVARAO \\ Department of Food Engineering, Central Food Technological Research Institute, Council of Scientific and Industrial Research, Mysore 570 \\ 020, India
}

Received March 10, 2010; Accepted June 13, 2010

Hot air assisted infrared (IR) drying of potato and carrot is carried out and product quality is compared with hot air dried samples. The synergistic effect of hot air and IR during combined mode (hot air assisted IR) drying reduced the processing time by nearly $\mathbf{4 8 \%}$ as compared to hot air drying alone, besides improving the quality of products. Higher rehydration ratio and lower browning index values are observed for combined mode dried products. Photomicrographs of dehydrated carrot and potato showed superiority of product structure for combined mode dried products. The IR dried carrot had higher (by $17 \%$ ) retention of carotenoid than hot air dried sample. The processing conditions such as velocity and temperature of air affected the drying characteristics during combined mode drying. Higher values of effective diffusivity of water are observed with combined mode drying.

Keywords: carotenoid, carrot, combined mode, hot air, infrared, potato

\section{Introduction}

Drying of food products is one of the most common processes used to improve the stability, as it decreases the water activity of product, in turn reduces microbiological activity and minimizes physical and chemical changes during storage (Mayor and Sereno, 2004). Hot air drying is the most commonly employed commercial technique for drying of food materials. However, low energy efficiency, longer drying time and poor product quality are some of the drawbacks of hot air drying. Newer drying techniques that have been attempted for drying are field assisted methods, which include dielectric heating (radio frequency and microwave), electromagnetic heating (infrared), inductive heating, ohmic heating, and heating in the presence of external fields such as pulsed electric field, ultrasound and UV light. While the application of microwave for food dehydration is established to some extent, use of other techniques such as infrared and radiofrequency drying has gained momentum only in the recent past.

Application of IR heating is gaining popularity in food processing because of its definite advantages over conventional heating. Faster and efficient heat transfer, lower

*To whom correspondence should be addressed.

E-mail: hebbar@cftri.res.in processing cost, uniform product heating and better organoleptic and nutritional value of processed material are some of the important features of IR drying (Sandhu, 1986). Infrared drying has been investigated as a potential method for obtaining high quality dried food stuffs, including fruits, vegetables and grains (Abe and Afzal, 1997; Afzal and Abe, 1998, Hebbar and Rastogi, 2001; Zhu et al., 2002, Baysal et al., 2003, Celma et al., 2008).

Foodstuffs with high moisture content can be effectively dried using combination of two or more methods, as it provides the synergistic effect. Combined mode drying like convective-microwave (Andres et al., 2004; Araszkiewicz et al., 2007; Kowalski and Rybicki, 2004) and microwavevacuum (Giri and Prasad, 2007) have been successfully employed in order to improve the effectiveness of drying. In the recent past, a few studies on the application of IR for combined mode drying of food materials have been reported (Afzal et al., 1999; Mongpraneet et al., 2002; Hebbar et al., 2004; Jain and Pathare, 2004; Praveenkumar et al., 2005; Pathare and Sharma, 2006; Swasdisevi et al., 2007; Reyes et al., 2008; Mihoubi et al., 2009; Kowalski and Rajewska, 2009). During combined IR and hot air drying, the rapid heating of food materials by IR radiation (due to high heat density and depth of penetration) increases the rate of moisture migration towards the surface, while the convective air- 
flow ensures the swift removal of moisture from the surface there by aiding in maintaining the moisture gradient (driving force). Afzal et al. (1999) studied the energy and quality aspects of combined far IR and convective drying of barley and observed substantial reduction in energy consumption in combined drying. Hebbar et al. (2004) reported the development of continuous combined IR and hot air dryer for handling fruits and vegetables. Studies on combined IR and hot air drying of onions indicated an improvement in product quality as compared to hot air drying (Praveenkumar et al., 2005). The combination of IR, microwave and hot air for drying of food materials was investigated by Datta and $\mathrm{Ni}$ (2002).

Although, reports on the application of IR and hot air for drying are available, no report on the product quality evaluation and effect of processing parameters during combined mode dried potato and carrot (widely used vegetables in the dehydrated form) are available. Hence, the present investigation is focused on i) comparing the performance (in terms of product quality) of hot air assisted IR drying with that of hot air and IR drying, carried out individually, ii) studying the effect of processing conditions such as velocity and temperature of air on drying characteristics during combined mode drying and iii) estimating effective diffusivity for different modes of drying.

\section{Theoretical considerations}

Diffusivity When liquid diffusion of moisture controls the rate of drying in the falling rate period the equation for diffusion described by Fick's second law of unsteady state diffusion can be used (Crank, 1975). Since, sample thickness is much less than its diameter/length, both the samples were assumed as infinite plane/slab. The following assumptions/boundary conditions were employed for the estimation of diffusivity.

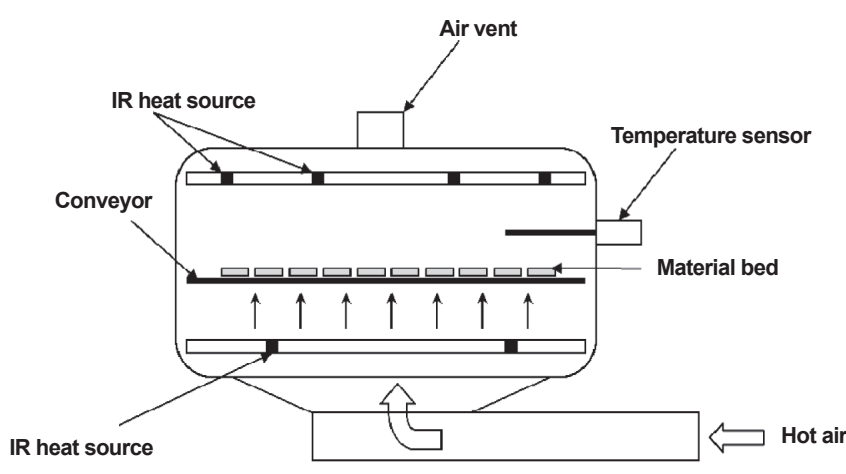

Fig. 1. Schematic diagram of combined infrared and hot air drying chamber.
1) Mass transfer is by diffusional mechanism

2) Moisture is initially $(t=0)$ distributed uniformly throughout the mass of a sample

3) Mass transfer is symmetric with respect to the centre

4) Resistance to mass transfer at the surface is negligible compared with internal resistance of the sample $-D \frac{d c}{d x} \ll k \Delta c$

5) Shrinkage of particles during drying does not alter the shape of the product significantly

$\frac{\mathrm{d} M}{\mathrm{~d} t}=D \frac{\mathrm{d}^{2} M}{\mathrm{~d} L_{\mathrm{T}}^{2}}$

The above equation may be integrated and can be written as;

$$
\begin{aligned}
\frac{M-M_{\mathrm{e}}}{M_{\mathrm{O}}-M_{\mathrm{e}}}= & \frac{8}{\pi^{2}}\left(\exp \left(-D t \frac{\pi^{2}}{4 L_{\mathrm{T}}{ }^{2}}\right)+\frac{1}{9} \exp \left(-9 D t \frac{\pi}{4 L_{\mathrm{T}}{ }^{2}}\right)^{2}\right. \\
& \left.+\frac{1}{25} \exp \left(-25 D t \frac{\pi}{4 L_{\mathrm{T}}{ }^{2}}\right)^{2}+\cdots+\right\}
\end{aligned}
$$

For long drying time, a limiting form of the above equation can be obtained (straight line form) as below (Celma et al., 2008)

$$
\ln \left(\frac{M-M_{\mathrm{e}}}{M_{0}-M_{\mathrm{e}}}\right)=\ln \left(\frac{8}{\pi^{2}}\right)-t D_{\mathrm{eff}}\left(\frac{\pi}{2 L_{\mathrm{T}}}\right)^{2}
$$

The above equation was used for the estimation of effective diffusivity.

\section{Materials and methods}

Materials The locally available fresh potato (Solanum tuberosum L.) and carrot (Daucus carota L.) having initial moisture content of $\sim 87 \%$ and $\sim 91 \%$ (w.b), respectively were used for the experimentation. The sample preparation involved washing, peeling, cutting $(17 \times 17 \times 5 \mathrm{~mm})$ of potato and slicing ( $25 \mathrm{~mm}$ diameter $\times 5 \mathrm{~mm}$ ) of carrot mechanically, sulphiting (1\% Potassium Metabisulphite) and water blanching $\left(90^{\circ} \mathrm{C}\right.$ for $\left.5 \mathrm{~min}\right)$.

Experimental set-up Pilot scale unit of continuous combined IR and hot air dryer (Fig. 1) developed by CFTRI, Mysore (Hebbar and Ramesh, 2002; Hebbar et al., 2004) was used to carry out the experiments. The three chambers $(1.1 \mathrm{~m} \times 0.9 \mathrm{~m}$ each) of this drying are fitted with infrared heat sources $(17 \mathrm{~kW})$ on either side of the conveyor. A stainless steel (AISI 304) wire mesh conveyor was used to carry the material through the heating chambers. The wire mesh conveyor allowed the maximum exposure of the material to the radiation coming from the bottom, in addition to facilitating through-flow hot air movement. Quartz Mid infrared (peak wave length in the range of $2.4-3.0 \mu \mathrm{m}$ ) tubes (surface temperature: $1070 \mathrm{~K}$ ) of $1.0 \mathrm{~m}$ length were employed for heating. A finned tube electrical heater of $15 \mathrm{~kW}$ and an axial flow blower connected with duct was used for hot air generation and distribution. 
Experimentation $3.0 \mathrm{~kg}$ of prepared vegetable was used in all the experiments and the unit was operated in batch mode. Monolayer of the vegetable was spread uniformly on the wire mesh conveyor and the drying temperature was maintained at $80 \pm 2^{\circ} \mathrm{C}$ for both the vegetables. The dryer was operated in three different modes, namely, hot air, IR and combination of hot air and IR. In the case of hot air mode drying, air heated to $80^{\circ} \mathrm{C}$ was used to maintain the drying temperature. IR heaters alone were used to dry the material at desired temperature $\left(80^{\circ} \mathrm{C}\right)$ in IR mode. Combination of infrared heater and mildly heated air $\left(40^{\circ} \mathrm{C}\right)$ controlled the drying temperature $\left(80^{\circ} \mathrm{C}\right)$ during combined mode drying. The airflow velocity was maintained at $1.4 \mathrm{~m} / \mathrm{s}$ during hot air and combination mode drying. For studies on effect of air temperature and velocity, the set values were changed to $28^{\circ} \mathrm{C}$ and $0.8 \mathrm{~m} / \mathrm{s}$, respectively, while maintaining all other conditions the same. The air temperature and air flow velocities were measured at five different points ( 4 corners and center) inside the drying chamber and average values were used. Product temperature was measured using non-contact type IR thermometer at different time intervals and average value was used. The samples were drawn at regular intervals for moisture analysis.

Analyses The moisture content of the raw and dehydrated samples were measured by oven drying method (Ranganna, 1977) and expressed on percentage wet basis. The carotenoid content in raw and dehydrated carrot was estimated spectrophotometrically (Ranganna, 1977). The carotenoid values were expressed as $\mathrm{mg} / 100 \mathrm{~g}$ of sample. All the measurements were made in triplicate and average values have been reported.

Rehydration ratio Rehydration ratio of dehydrated samples was estimated using the equation given below (Ranganna, 1977).

Rehydration ratio $=\left[\frac{\text { Drained weight of rehydrated sample }}{\text { Weight of sample used for dehydration }}\right]$
Color values The color values $(L, a, b)$ of carrot and potato samples were measured using color measuring system (Hunter Lab, USA, Lab Scan XE, C Illuminant, 2 view angle). The powder obtained by grinding the dried material in a domestic mixer was used for color estimation. The browning index $(B I)$ that indicates the purity of brown color was estimated using the equations given below (Maskan, 2001).

$$
\begin{aligned}
& B I=\frac{[100(x-0.31)]}{(0.17)} \\
& x=\frac{(a+1.75 L)}{(5.645 L+a-3.012 b)}
\end{aligned}
$$

Microscopic structure The samples were placed on the scotch tape fixed to a metal stub and gold coated (about $100 \AA$ ). The gold coated samples were scanned in a scanning electron microscope (model: Leo $435 \mathrm{VP}, \mathrm{M} / \mathrm{s}$ Leo Electron Microscopy, UK) and the selected portions were photographed.

\section{Results and discussion}

Drying rate curve The drying of carrot slices and potato slabs were continued till the moisture content reached the desired level of $7-8 \%$ (w.b). The time required for drying both the vegetables under different modes is presented in Table 1. The reduction in drying time was nearly $48 \%$ and $17 \%$ with combination mode and IR drying, respectively as compared to hot air drying. The significant reduction in drying time with combination mode could be attributed to the synergistic effect of IR and hot air. The rapid diffusion of moisture to the surface of material due to IR heating and simultaneous removal of moisture from the surface by forced convection resulted in a quicker drying process. The higher drying time in IR mode could be attributed to natural convective flow of air, which is slower than that compared to forced convection in combined mode drying. The moisture content values obtained at different intervals of drying time were used for the estimation of drying rate. The drying rate curves (Figures

Table 1. Drying time and moisture content for carrot and potato under different modes of drying ${ }^{\mathrm{a}}$.

\begin{tabular}{lllcr}
\hline \multirow{2}{*}{ Material } & Mode of drying & \multicolumn{2}{c}{ Moisture content (\% w.b) } & Drying time (min) \\
\cline { 3 - 5 } Carrot & Hot air & Initial & Final & 345 \\
& IR & $90.62 \pm 1.61$ & $7.14 \pm 0.15$ & 285 \\
& Combined & $90.71 \pm 1.34$ & $7.02 \pm 0.10$ & 195 \\
& Hot air & $90.55 \pm 1.42$ & $7.53 \pm 0.12$ & 345 \\
& IR & $86.03 \pm 1.31$ & $7.80 \pm 0.15$ & 285 \\
& Combined & $86.32 \pm 1.20$ & $7.76 \pm 0.10$ & 195 \\
\hline
\end{tabular}

\footnotetext{
${ }^{\text {a }}$ drying temperature $80^{\circ} \mathrm{C}$, air velocity $1.4 \mathrm{~m} / \mathrm{s}$
} 
2 and 3) indicated a higher rate of moisture removal with IR as well as combined mode. For both the vegetables, only the falling rate period was observed in all the three modes of heating. Higher drying temperature as well as effect of IR radiation could be responsible for the above observation. Sharma and Prasad (2001) and Prabhajan et al. (1995) also observed similar trends during combined microwave and hot air drying of garlic cloves and carrot slices, respectively. The reduction in drying time could lead to improved quality of products, besides consuming lesser energy for processing.

Rehydration characteristics The rehydration characteristics of the dried material are always used as an index of structural quality, and it largely depends on the drying conditions employed. The rehydration ratios estimated for carrot and potato dried under different modes are presented in Table 2. The higher rehydration ratios with IR $(2.9 \%$ and $5.6 \%)$ and combined mode (11.4\% and $12.5 \%)$ dried potato and carrot indicated an improved product structure as compared to hot air dried samples. Uniform and rapid heating by IR radiation, and absence of case hardening might have been responsible for the above observation. Rapid heating with IR and quicker diffusion of water vapor within the material might be facilitating the sample to retain its porous structure, increasing its ability to absorb higher amount of water during rehydration. Baysal et al. (2003) had reported higher rehydration capacity of infrared dried carrot as compared to that dried using hot air or microwave.

Carotenoid content in carrot The carotenoid and chlorophyll retention are very important in determining the final quality of thermally dehydrated green or high carotenoid content vegetables. Both carotenoid and chlorophyll are sensitive to heat, oxygen, light, and enzymes, whereas the chlorophyll is also sensitive to $\mathrm{pH}$ and heavy metals (Cui et al., 2004). The retention of carotenoid in carrot dried under different modes is provided in Figure 4. The carotenoid retention was higher by $17 \%$ and $14 \%$ in IR dried and combined mode dried samples respectively, as compared to that dried by hot air. The increased carotenoid retention in samples dried with IR may be attributed to reduction in dry-

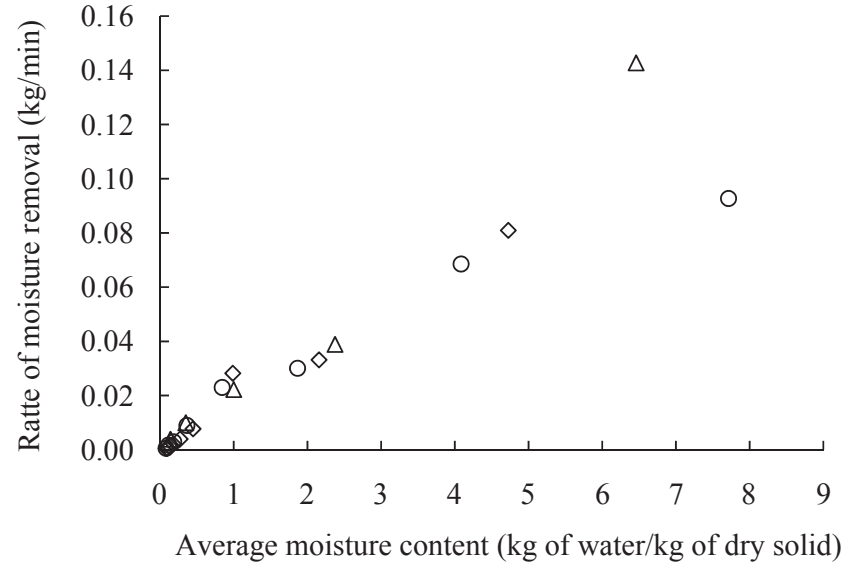

Fig. 2. Plot of average moisture content and rate of moisture removal for carrot. Open square, hot air; Open circle, infrared; Open triangle, combined mode.

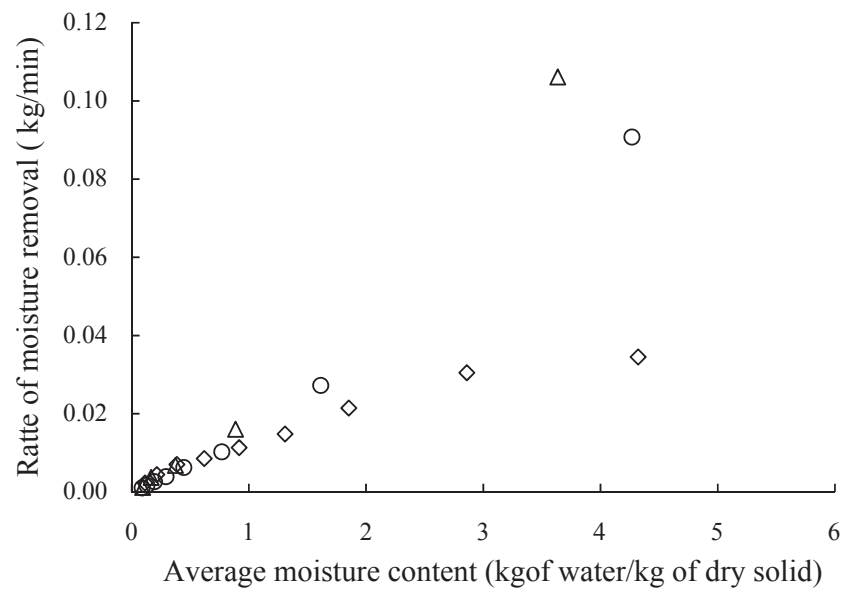

Fig. 3. Plot of average moisture content and rate of moisture removal for potato. Open square, hot air; Open circle, infrared; Open triangle, combined mode.

ing time and minimized the oxidation loss. The marginally lower carotenoid retention with combined mode may be attributed to higher oxidation loss associated with convective airflow. Cui et al. (2004) had studied the effect of different drying methods on carotenoid retention in carrot slices, and reported that carotenoid retention was lower in combination of microwave-vacuum and hot air than drying by micro-

Table 2. Quality characteristics and effective diffusivity of potato and carrot dried under different modes.

\begin{tabular}{|c|c|c|c|c|c|c|}
\hline \multirow[t]{2}{*}{ Mode of drying } & \multicolumn{2}{|c|}{ Rehydration ratio } & \multicolumn{2}{|c|}{ Browning index $(\mathrm{BI})$} & \multicolumn{2}{|c|}{ Effective diffusivity $\left(\mathrm{m}^{2} \mathrm{~s}^{-1}\right)$} \\
\hline & Potato & Carrot & Potato & Carrot & Potato & Carrot \\
\hline Hot air & $7.03 \pm 0.04$ & $7.23 \pm 0.02$ & $42.53 \pm 1.11$ & $107.49 \pm 1.12$ & $1.37 \times 10^{-8}$ & $2.28 \times 10^{-8}$ \\
\hline IR & $7.21 \pm 0.03$ & $7.57 \pm 0.06$ & $38.77 \pm 0.62$ & $106.07 \pm 0.85$ & $2.73 \times 10^{-8}$ & $3.29 \times 10^{-8}$ \\
\hline Combined & $7.84 \pm 0.05$ & $8.05 \pm 0.04$ & $32.48 \pm 0.44$ & $100.53 \pm 0.72$ & $3.65 \times 10^{-8}$ & $4.81 \times 10^{-8}$ \\
\hline
\end{tabular}




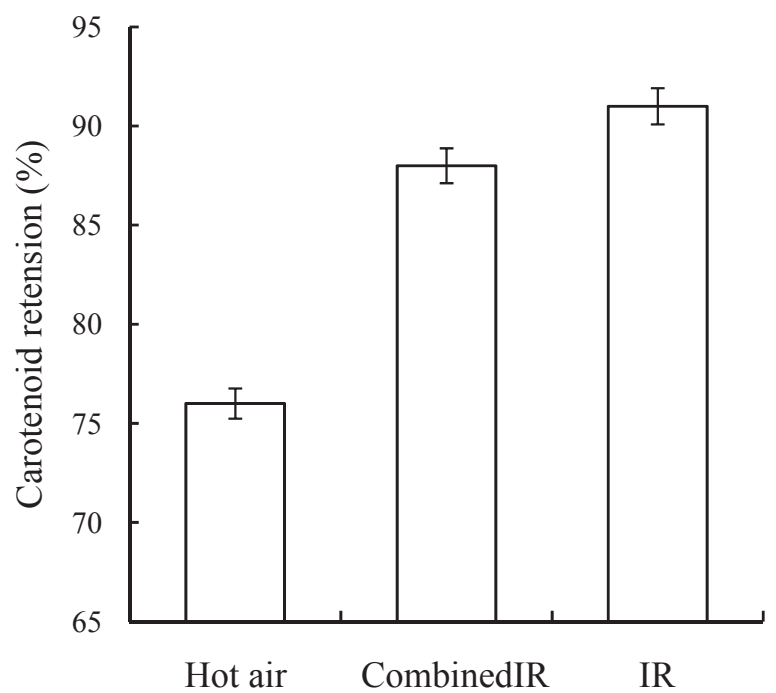

Fig. 4. Carotenoid retention in carrot samples dried under different modes.
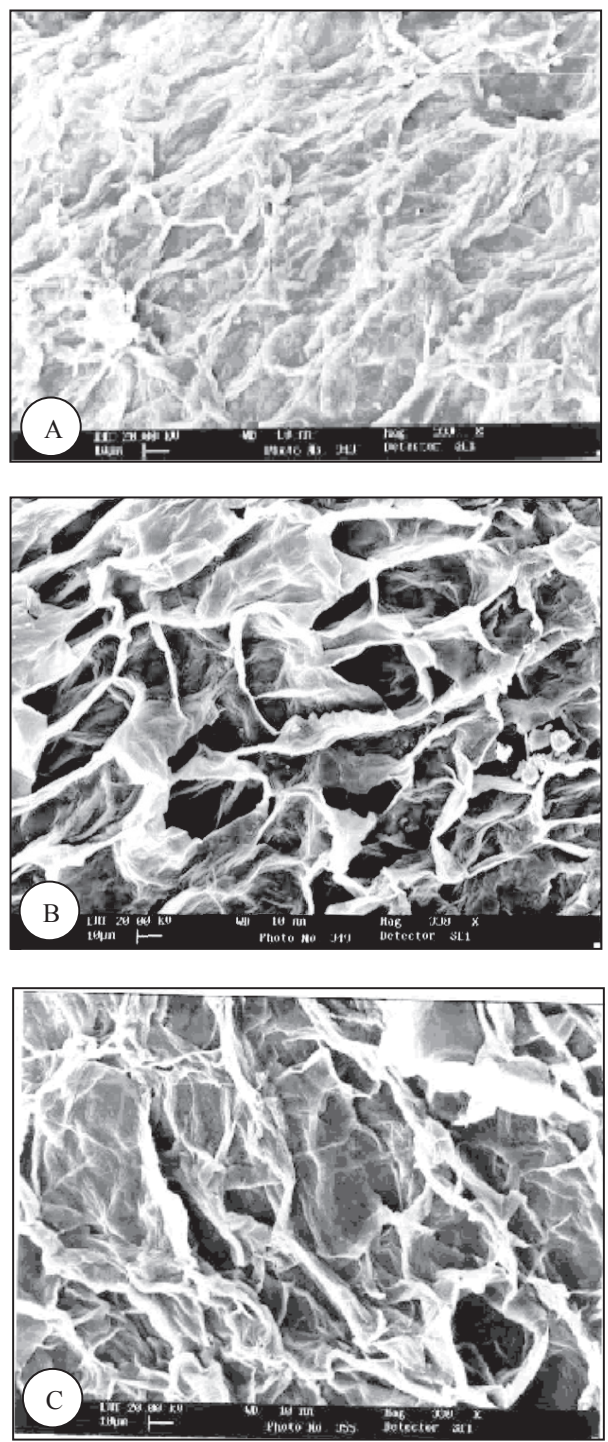

Carrot (500X) wave-vacuum. Loss of carotenoids when exposed to air and high temperature is attributed to oxidation of unsaturated carotenoids molecules, and also the isomerization of transcarotenoid to the light colored cis-forms (Cui et al., 2004). The same reasoning may be ascribed to the observation made in the present study during combined mode and hot air mode drying.

Scanning electron micrograph (SEM) Figure 5 shows the photomicrographs of dehydrated carrot and potato dried under different modes of drying. Cell structure of hot air dried sample appeared to be flattened or damaged, whereas it was more intact and porous (large pore size) in samples dried under IR and combined mode. Rapid heating and vapor diffusion within the material during IR or combined mode drying has resulted in a porous structure in the product. Reyes et al. (2008) had reported that in terms of microstructure of
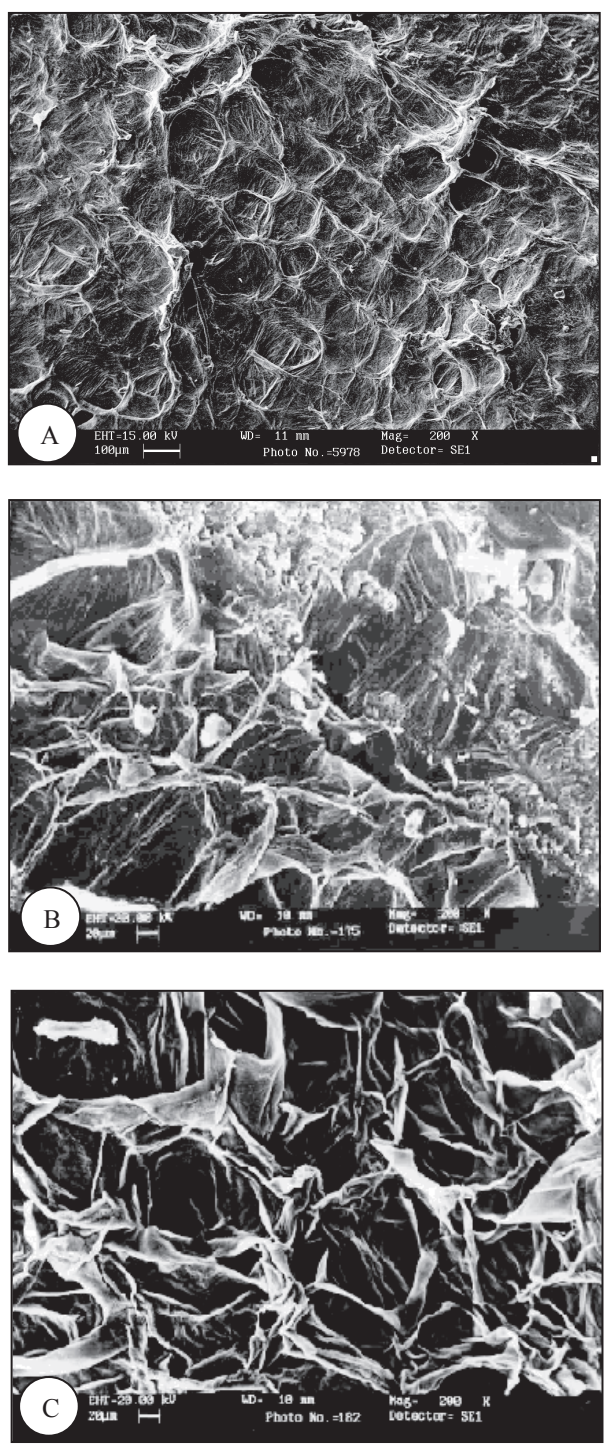

Potato (200X)

Fig. 5. Photomicrographs of carrot and potato (A-Hot air, B-IR, C-Combined mode dried samples). 
dehydrated carrot, application of IR radiation was better as compared to hot air drying. Larger pore size indicates that there are much wider intracellular channels, which makes water transport and migration quicker and easier during rehydration. The similar results obtained in the present study are in conjunction with the observation made during rehydration study.

Color measurement The product color undergoes change during processing and the extent of change depends upon the severity of conditions employed. The product color measured by colorimetric method was used to estimate browning index $(B I)$, which indicates the purity of brown color. Table 2 shows the BI values for carrot and potato dried under different modes of drying. For the combined mode samples the values were lower by $6 \%$ \& $24 \%$ than that of hot air mode dried carrot and potato, respectively. Although, IR dried samples developed more color during drying, the $B I$ values were lower than that of hot air dried samples. Higher BI value with hot air mode was due to the longer period of drying and case hardening of product, whereas, it could be due to increase in surface temperature in case of IR mode drying. Reduced drying time combined with relatively lower surface temperature due to convective heating, has resulted in better product color in case of combined mode drying.

Effect of processing conditions In order to study the effect of convective heating the process parameters such as velocity and temperature of air used during combination mode drying of potato were varied. Since, the above two parameters contribute to energy requirement of the process and hence process economics, the effect of these two parameters were studied. Figure 6 gives the moisture curve for potato dried at two different air velocities, namely, 0.8 and $1.4 \mathrm{~m} / \mathrm{s}$, while maintaining the other processing conditions the same. An increase in drying time by nearly 30\% was observed when airflow velocity was reduced from 1.4 to $0.8 \mathrm{~m} / \mathrm{s}$. The increase in drying time may be attributed to the incomplete removal of moisture from the surface by air at lower velocity. This in turn reduces the moisture gradient between the surface and inner layers of the material, resulting in lower mass transfer. It is reported that increase in air velocity beyond a level will have a negative effect on mass transfer, as it rapidly cools the surface (Ginzburg, 1969).

To study the effect of air temperature on drying, the air at room temperature $\left(26 \pm 2{ }^{\circ} \mathrm{C}\right)$ was used during combination mode drying. The lowering of air temperature increased the drying time by $48 \%$ as compared to drying with air at $40^{\circ} \mathrm{C}$ (Figure 7). The cooling of the material surface due to lower air temperature, resulted in lower evaporation rate and hence the extended period of drying. However, very high air temperature could lead to casehardening of the product resulting in its poor quality. Hence, there is a need to optimize both the air velocity and temperature to effectively dry the material during combination mode. Similar results were reported by Sharma et al. (2005) during drying of onion slices using laboratory scale infrared-convective system.

Effective mass diffusivity Diffusion of moisture controls the rate of drying in the falling rate period and increase in effective diffusivity is an indicator of lower resistance

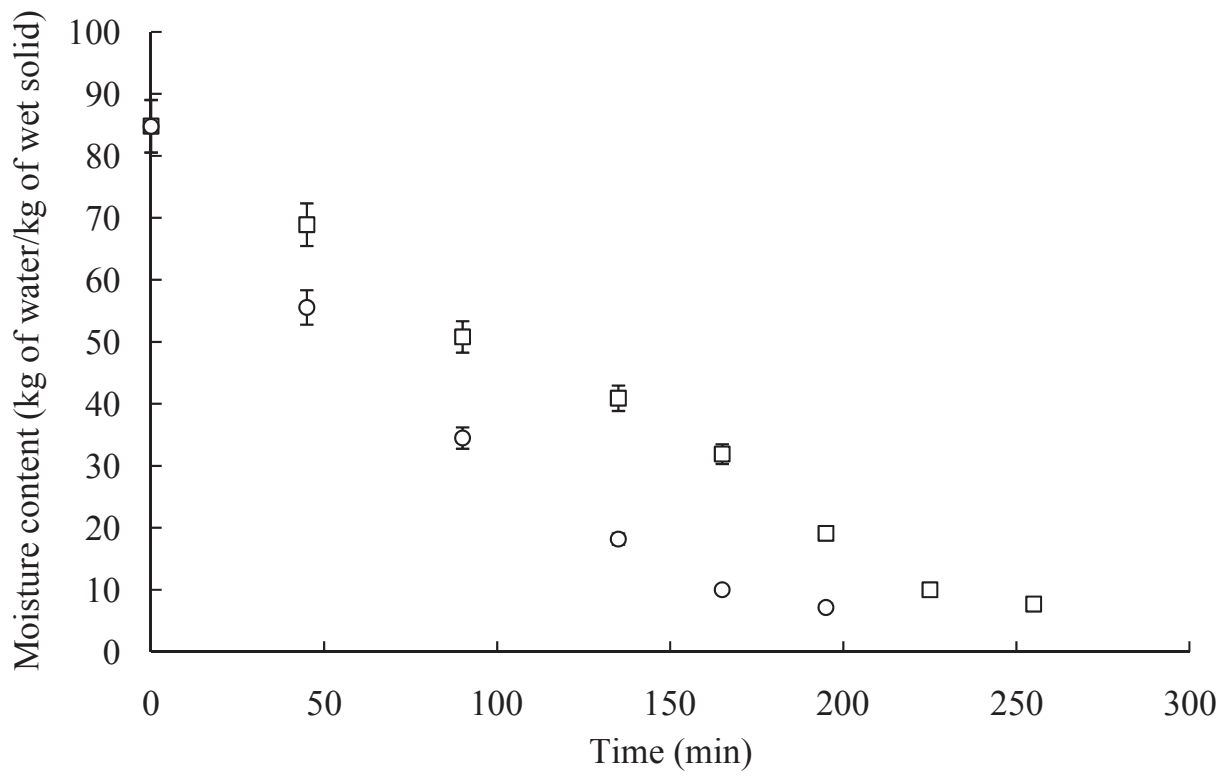

Fig. 3. Moisture curve of potato dried at different air velocities under combined mode drying (Drying temperature $80^{\circ} \mathrm{C}$, air temperature $40^{\circ} \mathrm{C}$ ). Open square, $0.8 \mathrm{~m} / \mathrm{s}$; Open circle, $1.4 \mathrm{~m} / \mathrm{s}$. 


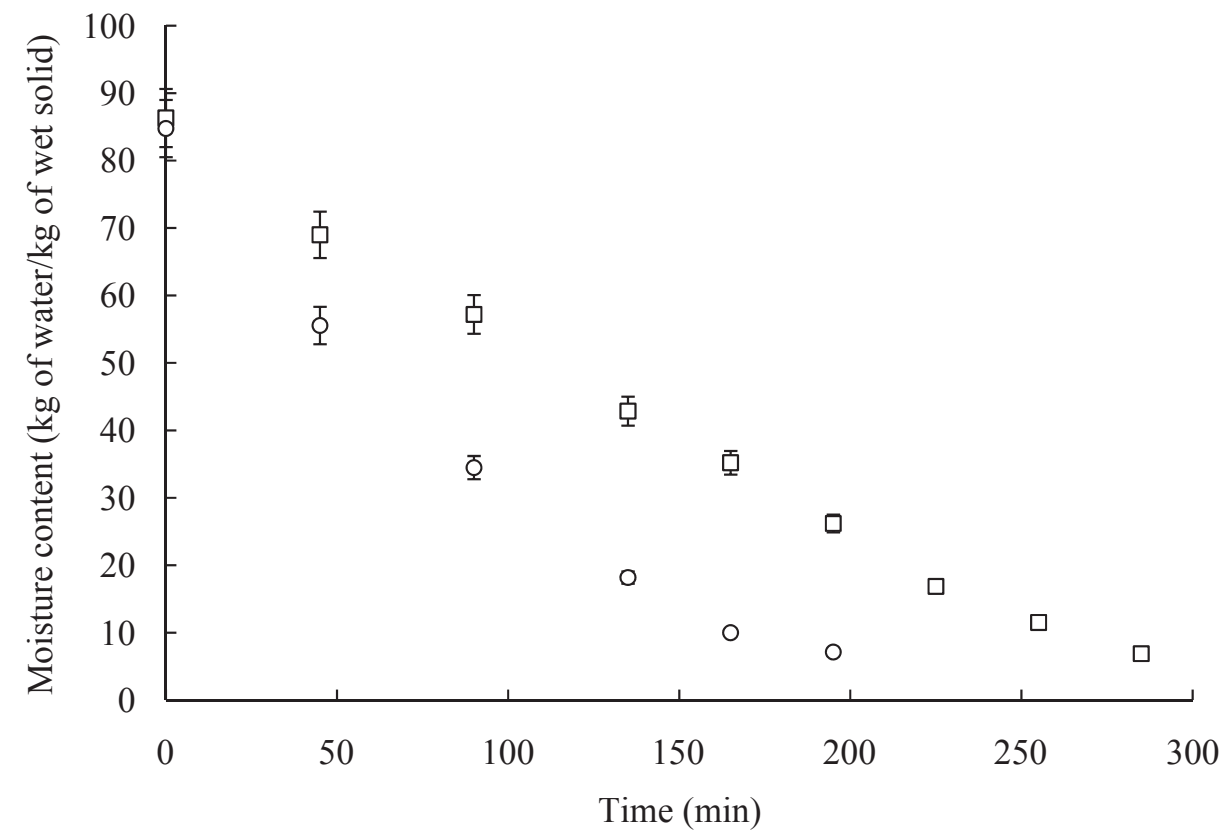

Fig. 7. Moisture curve of potato dried at different air temperature under combined mode drying (Drying temperature $80^{\circ} \mathrm{C}$, air velocity $1.4 \mathrm{~m} / \mathrm{s}$ ). Open square, $28^{\circ} \mathrm{C}$; Open circle, $40^{\circ} \mathrm{C}$.

to mass transfer in the material being dried. The diffusivity of water or vapor during drying is dependent on product structure and gradient (moisture, vapor pressure) across the product surface and inner layers. The equation for slab geometry obtained by applying Fick's law of diffusivity for moisture diffusion through the solids was used for the estimation (Geankoplis, 2000) and the values are presented in Table 2. The effective diffusivity values for combined mode drying was slightly higher $\left(3.65 \times 10^{-8} \& 4.81 \times 10^{-8}\right)$ as compared to hot air drying $\left(1.37 \times 10^{-8} \& 2.28 \times 10^{-8}\right)$ in potato and carrot, respectively. The IR mode of drying also gave higher diffusivity values $\left(2.73 \times 10^{-8} \& 3.29 \times 10^{-8}\right)$ than hot air drying, although it was lower than the combined mode diffusivity. The effective diffusivity values observed in the present study are close to that reported (Panagiotou et al., 2004) for potato (between $1.25 \times 10^{-8}$ and $8.0 \times 10^{-12} \mathrm{~m}^{2} / \mathrm{s}$ in temperature ranges $24-185^{\circ} \mathrm{C}$ ) and for carrot (from $7.46 \times 10^{-9}$ to $2.20 \times$ $10^{-12}$ in the temperature range $20-100^{\circ} \mathrm{C}$ ). Rapid increase in product temperature due to exposure to IR, higher gradient for moisture diffusion due to vapor pressure difference between the surface and inner layers and, retention of product structure (porous as shown in Fig. 5) during drying under combined and IR mode could be responsible for the observed higher diffusivity. Rapid removal of water from the product surface by convective airflow leading to higher moisture gradient might have resulted in higher diffusivity values of combined mode dried product as compared to drying with IR alone. Internal diffusion of moisture being the rate control- ling mechanism during falling rate period, it was observed that the processing conditions indirectly influenced the moisture diffusion and thereby altered the drying rate.

Acknowledgements The authors wish to thank the Department of Science and Technology, New Delhi for the award of research grant to develop the infrared dryer (\#IDP/FP/14/98). The authors also thank Dr. V Prakash, Director, CFTRI, Mysore for the kind support and encouragement. We thank Dr. S. G. Prapulla, and late Dr. M. N. Ramesh, Scientists, CFTRI for the valuable advice in carotenoid analysis.

\section{References}

Abe, T. and Afzal, T.M. (1997). Thin layer infrared radiation drying of rough rice. J. Agri. Eng. Res., 67, 289-297.

Afzal, T.M. and Abe, T. (1998). Diffusion in potato during far infrared radiation drying. J. Food Eng., 37, 353-365.

Afzal, T.M., Abe, T. and Hikida, Y. (1999). Energy and quality aspects during combined FIR-convective drying of barley. J. Food Eng., 42, 177-182.

Andres, A., Bilbao, C. and Fito, P. (2004). Drying kinetics of apple cylinders under combined hot-air microwave dehydration. $J$. Food Eng., 63, 71-78.

Araszkiewicz, M., Koziol, A., Lupinska, A. and Lupinski, M. (2007). Microwave drying of various shape particles suspended in an air stream. In "Drying of Porous Materials," ed. by S.J. Kowalski, Springer, pp. 173.

Baysal, T., Icier, F., Ersus, S. and Yildiz. (2003). Effects of micro- 
wave and infrared drying on the quality of carrot and garlic. Eur. Food Res. Technol., 218, 68-73.

Celma, A.R., Rojas, S. and Rodriguez, F.L. (2008). Mathematical modeling of thin layer infrared drying of wet olive husk. Chem. Eng. Proces., 47, 1810-1818.

Cui, Z.W., Xu, S.Y. and Sun, D.W. (2004). Effect of microwavevacuum drying on the carotenoids retention of carrot slices and chlorophyll retention of Chinese chive leaves. Drying Technol., 22(3), 563-575.

Datta, A.K. and Ni, H. (2002). Infrared and hot air assisted microwave heating of foods for control of surface moisture. J. Food Eng., 51, 355-364.

Geankoplis, C.J. (2000). “Transport process and unit operation.” $3^{\text {rd }}$ edition, Prentice-Hall of India, New Delhi.

Ginzburg, A.S. (1969). "Application of infrared radiation in food processing.” Leonard Hill Books, London.

Giri, S.K. and Prasad, S. (2007). Drying kinetics and rehydration characteristics of microwave-vacuum and convective hot air dried mushrooms. J. Food Eng., 78, 512-521.

Hebbar, U.H. and Ramesh, M.N. (2002). Combined infrared and convective heating system for food processing. Indian Patent application, 336/DEL/02.

Hebbar, U.H. and Rastogi, N.K. (2001). Mass transfer during infrared drying of cashew kernel. J. Food Eng., 47, 1-5.

Hebbar, U.H., Vishwanathan, K.H. and Ramesh, M.N. (2004). Development of combined infrared and hot air dryer. J. Food Eng., 65, 557-563.

Jain, D. and Pathare, P.B. (2004). Selection and evaluation of thin layer drying models for infrared radiative and convective drying of onion slices. Biosystems Eng., 89(3), 289-296.

Kowalski, S.J. and Rajewska, K. (2009). Effectiveness of hybrid drying. Chem. Eng. Process., In press, doi:10.1016/ j.cep.2009.05.009.

Kowalski, S.J. and Rybicki, A. (2004). Qualitative aspects of convective and microwave drying of saturated porous material, Drying Technol., 22(5), 1173-2118.

Maskan, M. (2001). Drying, shrinking and rehydration characteristic of kiwi fruit during hot air and microwave drying. J. Food
Eng., 48, 177-182.

Mayor, L. and Sereno A.M. (2004). Modeling shrinkage during convective drying of food materials: A review. J. Food Eng., 61, 373-386.

Mihoubi, D., Timoumi, S. and Zagrouba, F. (2009). Modeling of convective drying of carrot slices with IR heat source. Chem. Eng. Proces., 48, 808-815.

Mongpraneet, S., Abe, T. and Tsurusaki, T. (2002). Accelerated drying of welsh onion by far infrared radiation under vacuum conditions. J. Food Eng., 55, 147-156.

Panagiotou, N.M., Krokida, M.K., Maroulis, Z.B. and Saravacos, G.D. (2004). Moisture Diffusivity: Literature Data Compilation for Foodstuffs. Int. J. Food Prop., 7(2), 273-299.

Pathare, P.B. and Sharma, G.P. (2006). Effective moisture diffusivity of onion slices undergoing infrared convective drying. Biosystems Eng., 93(3), 285-291.

Prabanjan, D.G., Ramaswamy, H.S. and Raghavan, G.S.V. (1995). Microwave assisted convective air-drying of thin layer carrots. $J$. Food Eng., 25, 283-293.

Praveenkumar, D.G., Hebbar, U.H., Debnath, S.D. and Ramesh, M.N. (2005). Infrared and hot-air drying of onions. J. Food Proces. Pres., 29, 132-150.

Ranganna, S. (1977). "Manual of analysis fruits and vegetables." Tata McGraw-Hill, New Delhi.

Reyes, A., Vega, R., Bustos, R. And Araneda, C. (2008). Effect of Processing Conditions on Drying Kinetics and Particle Microstructure of Carrot. Drying Technol., 26, 1272-1285.

Sandhu, C. (1986). Infrared radiative drying in food engineering: A process analysis. Biotech. Prog., 2, 109-119.

Sharma, G.P. and Prasad, S. (2001). Drying of garlic (Allium Sativium) cloves by microwave hot air combination. J. Food Eng., 50, 99-105.

Sharma, G.P., Verma, R.C. and Pathare, P. (2005). Mathematical modeling of infrared radiation thin layer drying of onion slices. $J$. Food Eng., 71, 282-286.

Zhu, K., Zou, J., Chu, Z. and Li, X. (2002). Heat and mass transfer of seed drying in a two pass infrared radiation vibrated bed. Heat Transfer-Asian Res., 31(2), 141-147. 